Archived version from NCDOCKS Institutional Repository http://libres.uncg.edu/ir/asu/ 2008. Review of Wei Zhang's Heidegger, Rorty, and the Eastern Thinkers (Albany: SUNY Press, 2006) in Sophia 47, 253-255. (ISSN: 0038-1527)

\title{
Review of Wei Zhang, Heidegger, Rorty, and the Eastern Thinkers: A Hermeneutic of Cross-Cultural Encounter Thomas B. Ellis
}

Wei Zhang's Heidegger, Rorty, and the Eastern Thinkers: A Hermeneutic of Crosscultural Encounter adds to a relatively small but significant and hopefully growing list of titles dedicated to exploring the problematic encounter between Western and Eastern philosophical traditions. Zhang's efforts are to be commended as she tackles difficult and often impenetrable topics, especially those topics pertaining to Heideggerian philosophy. Despite the occasional, insightful comment, I was a bit disappointed with the work as a whole. The four sections - (1) The Recurring EastWest Hermeneutic Riddle, (2) Richard Rorty's Correspondence with a Comparative Philosopher, (3) Martin Heidegger's Dialogue with a Japanese Visitor, and (4) A Conceptual Dialogue with Heidegger's Text on Hermeneutics - do not hang together very well. The rather cursory, introductory first section aside, the remaining three sections appear to be separate, disconnected essays. In the absence of a satisfying conclusion tying the three discussions together, the reader does not get the sense that he or she has been introduced to or persuaded of 'a hermeneutic of crosscultural encounter.' All the same, the attentive reader may in fact discern that Zhang endorses the notion that cross-cultural encounter is undertaken in the name of edification and eventual reduction of alterity: 'trying to proceed with caution from topics and issues that they are not familiar with... encouraging one to retrieve what would otherwise be overlooked or forgotten in one's own tradition only to discover what appeared to be foreign is actually already embedded as familiar in one's own tradition' (57). Such a suspiciously conservative hermeneutic has been rightly contested by such thinkers as Jarava Lal Mehta, Mark C. Taylor, and Jacque Derrida. Unfortunately, Zhang does not address this issue. For those familiar with the problems attending comparative philosophy, there is nothing truly new here; for those unfamiliar with such problems, I am afraid this book does not serve as an adequate introductory text. What's more, for those uninitiated in the notoriously abstruse 'Heideggerian speak,' Zhang fails to 'translate' the central philosophical issues into accessible language.

Perhaps reflective of the edification at the heart of Zhang's hermeneutic, a subtlethough most certainly unintended - Orientalism informs the text. Throughout 
Orientalist literature and strategy, one often finds the assignation of agency to the Western individual and the consequent relegation of the 'Eastern individual' to a group-determined response. Western individuals initiate; Eastern individuals represent. Especially in comparative philosophical discussions, we often find an individual Western philosopher compared to an 'Eastern school,' for example, 'Heidegger and Zen.' While Heidegger agentially determines his position, the Zen tradition putatively determines the position of the 'Eastern representative.' In classical Orientalist fashion, the assigned anonymity of 'Eastern thinkers' suggests the occlusion of their agency: the 'Eastern thinkers,' that is, the 'Comparative Philosopher' and the 'Japanese Visitor' ultimately react to Rortian and Heideggerian positions.

Rorty argues that 'philosophy,' that is, the search for essences is irreducibly Western, and as such, comparative philosophy is not a viable program. Balslev with whom Zhang is apparently most sympathetic — notes that Rorty is ethnocentric on this score. Balslev claims that Rorty's essentializing definition of philosophy as Western precludes the possibility that other cultures have philosophy. While Rorty may be rightly castigated for a certain ethnocentrism, he need not be reprimanded for his definitions as such. If 'philosophy' is to mean anything at all it must be defined, and definitions entail exclusions. If Balslev and Zhang dislike Rorty's definition, so be it. They ought to offer up some alternative. This we do not get here. The interesting point, however - and one apparently underappreciated by Balslev and Zhang - is that Rorty is not triumphalistic in his relegation of philosophy to the West. Indeed, having negotiated the post-metaphysical turn, Rorty is uninterested in any philosophical systems, West or East. As such, comparative philosophy — like philosophy in general - is a dead subject matter for this neo-pragmatist. To be fair to Rorty, we can easily imagine his endorsement of a comparative literature project in which the authors considered are Orwell, Nabokov, and Rushdie. Rorty is not anti-Other. He is anti-philosophy.

On precisely this issue of the other, I sense confusion in Zhang's presentation of Balslev. Balslev argues that Rorty dismisses the Other. Hardly. Rorty recognizes a difference between the philosophical Other and the anthropological other. As one uninterested in philosophy, Rorty may be equally uninterested in the philosophical discussions of alterity. Of course, and on one significant register, these discussions have nothing to do with anthropological alterity. Thanks to Derrida, we know that the philosophical Other is every other: the cross-cultural other and the intra-cultural other are equally other. That being said, it is clear that Rorty is concerned with the anthropological other as he openly petitions for social and economic justice across all cultures. Philosophically speaking, the distinction between philosophical alterity and anthropological alterity is worth preserving, a preservation found wanting in Zhang's presentation of Balslev.

Zhang's third section appears to be a recapitulation of the exchange between Heidegger and the 'Japanese visitor' found in Heidegger's On the Way to Language. I did not find anything particularly new in this discussion. What is perhaps significant, however, is Zhang's recognition that this exchange is much more 
amicable than the one between Rorty and Balslev. Zhang does not comment on the potential reasons for the disparity. Perhaps we should. Heidegger and Tezuka find that they can come to a mutual understanding that language opens up a primordial realm of Being. Zhang notes, 'if there were a common language origin in both German and Japanese traditions, there might be an existing "shared" language world, regardless of the differences in actual speech of them, respectively... it would allow the speakers to bring themselves ever closer to the earthly nature and onto-cosmic origin of their existence'(64-65). Aside from the difficulties of discerning what precisely 'onto-cosmic origin' means, we must pause when an earthly, primordial Being trumps 'differences in actual speech.' As the American philosopher John D. Caputo rightly notes, Heideggerian discussions concerning primordial Being invoke a 'Nazi myth.' While Rorty and Balslev inherit a cultural history marked by antagonistic, colonial interests and contests, Heidegger and Tezuka share cultural histories marked by fascism. The German-Japanese philosophical amity presented here raises some interesting - though unaddressed - ethical concerns.

The final section introduces the reader to an early Heideggerian text-Ontology The Hermeneutics of Facticity. This section includes one of the more lucid expositions of the Heideggerian position, but the eventual comparison between Heidegger's 'family table' and the Chinese Buddhist Fa-tsang's discussion of two golden lions leaves much to be desired. Zhang does not in any way elucidate how Fatsang's 'gold' is empty (shunyata) nor does she clearly demonstrate the relevance of the two lions to Heidegger's hermeneutics. Lastly, Zhang makes a quick mention of the (dubious) relevance of Fritjof Capra's work to Eastern mysticism. In general, this final discussion seems thrown together and ultimately without connection to the two preceding discussions.

Rorty's position notwithstanding, I believe comparative philosophy is an interesting and potentially fruitful endeavor. I appreciate Zhang's interests in documenting the complex and difficult exchanges between Rorty and Balslev and Heidegger and Tezuka. All the same, and precisely because of the difficulties attending such comparative tasks, authors need to be precise and consistent about the terms they are using and the agenda they are pursuing. I am unconvinced that Zhang succeeds on this score. I also believe that it is time we adjust the comparative program. Instead of assuming the Western position and then turning to potential resonances in Eastern traditions, perhaps we should begin with the East and search for both resonances and differences in the West. In other words, it is time we pursue such comparisons by commencing with an 'Eastern thinker' rather than the 'Western thinkers.' 